\title{
AN ANALYSIS OF THE EFFECTS OF OIL PRICE SHOCKS ON THE COLORADO ECONOMY USING VECTOR AUTOREGRESSION
}

\author{
Alok K. Bohara
}

\section{Introduction}

In recent years, there have been various attempts to measure the effects of oil price increases on the macroeconomic performance of the United States. The general finding has been that rising oil prices cause wages and prices to increase and real output to decrease (see Bruno, 1982; Harkness, 1982; and Tatom, 1981). The effect of oil price shocks, on the other hand, may be quite different for a regional economy, especially for states that are heavily engaged in activities related to the oil and gas sector. Some of these states are Alaska, Colorado, Louisiana, Oklahoma, Texas, and Wyoming. Any upward oil price shock that may affect the macroeconomy adversely can, however, stimulate energy-related economic activities in the oil-producing states. But ultimate effects may well depend upon the overall industry mix and the various channels through which the oil price shocks are transmitted to the regional economy, both directly and via macrovariables. Hunt and Oldham (1986) identify four main channels through which oil-price shocks influence the Colorado economy. They are (1) employment and earnings in the Colorado oil and gas sector, (2) the consumer price index, (3) the national economy, and (4) tourism and recreation in Colorado. Hunt and Oldham use the Trezy, Friedlaender, Stevens (TFS) regional modeling technique to examine the impact of falling oil prices. Their findings suggest that employment and drilling activity in the oil and gas sector suffered as a result of the oil price collapse. But increased real personal income from the lower oil prices was found to offset the negative impacts in the oil sector. This finding contradicts the general perception that an oilproducing state such as Colorado suffers from falling oil prices. For detailed information about the TFS modeling approach, see Trezy and Stevens (1986).

This paper analyzes the effects of oil price shocks on the Colorado economy by using the innovation-accounting technique of Sims (1980) to study the channels of influence. The paper demonstrates that a time series model can be used to model a regional economy by integrating both

Assistant Professor, Department of Economics, University of New Mexico. The author would like to thank Dr. Robert F. McNown, University of Colorado, and three anonymous referees for their valuable comments. macro and regional factors in a vector autoregression.

This paper is organized as follows. The procedure is outlined in Section II. A brief discussion of the model and the variables included is presented in the Section III. Sections IV and V include the estimation and analysis of the results. Section VI gives the conclusions.

A six-variable vector autoregression containing three macrovariables (real oil price, interest rate and real GNP) and three regional variables (employment, real income, and consumer price index) is analyzed. The oil price variable is found to be exogenous to the entire system, and all three macrovariables are exogenous to the local economy. A positive oil price shock has been found to affect RGNP negatively. The influence of oil price shocks on employment and income in Colorado also is negative, meaning that, although it is an oil-producing state, Colorado does not benefit from a higher oil price. This result is similar to that of Hunt and Oldham (1986), in that they also found a negative relationship between the oil price and the Colorado economy. Their study examined the impacts of a lower oil price path, and concluded that the Colorado economy benefits from a falling energy price in spite of sluggish activities in the oil sector. Finally, real GNP seems to be an important factor for the Colorado economy.

\section{Study Procedure}

Unlike in the traditional econometric approach, time seriesmodels do notimpose any restrictions on the lead-lag structure and the endogeneity or exogeneity of the variables. By and large, the data are allowed to dictate the dynamic structure of the economic system. In this paper it is assumed that the only theoretical information available is the set of relevant variables to be included in the system. In addition, block exogeneity of the macro-variables is imposed with respect to the regional economy. This restriction is supported by the statistical tests.

Two types of times series models can be used to model an economic system. The first is the multiple autoregressive moving average (MARMA) model. and the second is the vector autoregression (VAR) model. This paper uses the VAR model mainly because the identification and estimation of a VAR model is relatively easier. Any model with a mixed process (MARMA) can be represented by a VAR with sufficiently large number of 
lags.

A VAR can be written as

where

$$
\emptyset(B) y_{t}=e_{t}
$$

$\emptyset(B)=$ an mxm matrix of polynomials in the back shift operator, $B$,

$\mathrm{m}=$ the number of variables in the system, and

$e_{t}=$ an mxl vector of white noise error processes with contemporaneous covariance matrix, $\Sigma$.

The modeling process is done in three stages: identification, estimation and diagnostic checks. The identification of a VAR process is based on final prediction error (FPE) criteria proposed by Caines, Keng and Sethi (1981). The proposed FPE criterion is used to determine the optimal lag length for each variable in each equation. In the final stage, all the equations with their optimal lags are estimated simultaneously (Fackler, 1985). As a check, in the VAR analysis based on FPE criteria, it usually is suggested to overfit the model. This paper uses a more comprehensive diagnostic checking procedure, in that the cross-correlation matrices at different lags are calculated for the residuals. Zero elements in the matrices are evidence of white noise and an indication of a clean diagnostic. A model with a clean diagnostic suggests that the dynamic structure implied by the model is compatible with the data. For more information, see, for example, Tiao and Box (1981) and Tiao and Tsay (1983).

Various channels of the influence of oil prices have been examined by calculating the impulse responses and the variance decompositions (see Bohara, Bradley, and McNown, 1987). The impulse responses are obtained by generating the moving average representation of the VAR,

or

$$
\begin{aligned}
& y_{t}=[\varnothing(B)]^{-1} e_{t} \\
& y_{t}=\pi(B) e_{t}
\end{aligned}
$$

$$
y_{t}=\sum_{k=0}^{\infty} \pi_{k} e_{t-k}
$$

Since the error e's are contemporaneously correlated, it seems appropriate to orthogonalize Equation (2) to get unique (uncorrelated) responses.

For a positive definite matrix $\Sigma$,

$$
L^{\prime}=\Sigma
$$

there are many ways to factor $\sum$ into LL'; one such method is the Choleski decomposition, in which $\mathrm{L}$ is a lower triangular non-singular matrix. Transforming Equation (2):

$$
y_{t}=\sum_{k=0}^{\infty}\left(\pi_{k} L\right)\left(L^{-1} e_{t-k}\right)
$$

or

$$
y_{t}=\sum_{k=0}^{\infty} \Psi_{k} a_{t-k}
$$

where the variance-covariance matrix of $a_{t}$ is an identity matrix. Impulse responses show how a particular variable responds, for example, to a positive unit shock in the price of oil.

An alternative descriptive measure for the analysis of the different channels of influence is considered next. The decomposition of the forecast error variance of each variable into shares attributable to each innovation is calculated by

$$
\xi_{t j}^{h}=\sum_{k=1}^{h} \sum_{i=1}^{m} \Psi_{k j i} a_{i t-k}
$$

where $\xi_{t \mathrm{j}}^{\mathrm{h}}=$ the $\mathrm{h}$ step ahead forecast error for $\mathrm{y}_{\mathrm{t} \mathrm{j}^{\circ}}$ This has a variance

$$
\sigma_{h j}^{2}=\sum_{k=1}^{h} \sum_{i=1}^{m} \Psi_{k j i}^{2}
$$

where $\Psi_{\mathrm{kji}}=$ the jith ${ }^{\text {th }}$ element of the matrix $\Psi_{\mathrm{k}}$. The amount of this variance due to innovations in the $i^{\text {th }}$ variable is

$$
\sum_{k=1}^{h} \Psi_{k j i}^{2} \text {. }
$$

A time series model, such as a VAR, allows testing for the exogeneity of a single variable or for the block exogeneity of a set of variables. The exogeneity of the first variable in a VAR implies that the coefficients associated with other variables in the first equation are equal to zero. This is tested by using a likelihood ratio test,

$$
(\mathrm{T}-\mathrm{b}) \ln \frac{\left|\sum_{\mathrm{r}}\right|}{\left|\sum_{\mathrm{u}}\right|} \sim \mathrm{x}_{[\mathrm{r}]}^{2}
$$

where

$\mathrm{T}=$ the number of observations,

$\mathrm{b}=$ the number of parameters estimated in the unrestricted model,

$\Sigma_{\mathrm{r}}\left|, \Sigma_{\mathrm{u}}\right|=$ the determinants of the error covari ance matrices in the restricted and unrestricted models, and

$\mathbf{r}=$ the number of restrictions.

This form is based on Wold (1954).

\section{The Model}

To analyze the impact of oil price shocks on the Colorado economy, a six-variable VAR model is considered. Three local variables of interest are real personal income (RPYCS), total non-farm employment (EECS), 
and the Colorado consumer price index (CPIC). Since the oil price influence also may be expressed through macroeconomic activity, two national variables also are included in the model: interest rates as measured by the three-month treasury bill rate (FYGN3) and real GNP (RGNP). The following structural model (SM) is postulated:

SM: [oil price I national variables I regional variables \}

where it is assumed that the structure of the above SM is not known. Zellner and Palm (1975) show that any SM can be reduced to time series models, namely univariate and transfer function models. Similarly, corresponding MARMA or VAR models also can be derived from these SMs (see Bohara, 1986). Hence, the corresponding reduced form (VAR) for the above SM can be written as

$$
\phi(B) y_{t}=e_{t} \text {. }
$$

Oil price fluctuations always have been external events for the U.S. economy, especially since the formation of the Organization of Petroleum Exporting Countries-and therefore can be considered as a variable exogenous to the system. Similarly, the two national variables, the interest rate and the GNP, also are considered exogenous to the Colorado economy. Thus, the oil price, interest rate, and GNP are introduced as a block of exogenous variables in the six-variable regional VAR model, with oil price also exogenous to the two national variables, RGNP and FYGN3. The restricted VAR is

$$
\left[\begin{array}{ccc}
\phi_{11}(B) & 0 & 0 \\
-\frac{\phi_{21}}{\phi_{31}} \frac{(B)}{(B)}-\frac{\phi_{22}}{\phi_{32}(B)}-\frac{0}{\phi_{33}(B)} & \frac{0}{B_{t}}
\end{array}\right]\left[\begin{array}{l}
x_{1 t} \\
x_{2 t} \\
y_{t}
\end{array}=\left[\begin{array}{l}
e_{1 t} \\
e_{2 t} \\
e_{3 t}
\end{array}\right](10)\right.
$$

where

$x_{1 t}=$ the oil price variable,

$x_{2 t}=$ the set of national variables, and

$y_{t}=$ the regional variables.

Additional zero restrictions and the lag length are determined by the FPE criterion. If the Model (10) passes the diagnostic check, indicating its compatibility with the data, the underlying dynamic structure shown by Equation (10) is considered to be valid. This further implies the existence of a corresponding structural model, for example Equation (8). The traditional, "top-bottom," approach utilized in estimating Model (8), requires stringent restrictions as to endogeneity/exogeneity and lead-lag structure, whereas the "bottom-up" time series approach permits the data to dictate the basic dynamic structure of the model. As indicated earlier, the role of economic theory is minimal in that theory is used only to select the relevant variables for the model. The two exogeneity propositions also implied by theory have been tested, using the likelihood ratio test.

All the variables are logged and differenced once to induce stationarity, and all variables are seasonally adjusted except for the interest rate that shows no seasonal pattern of behavior. The oil price series used here reflects the refiner's acquisition cost to refiners of crude oil, including both imported and domestic crude prices. To get the real oil price, the price series has been deflated by the GNP deflator. The consumer price index variable for Colorado is created from the price indices for Boulder and Denver. The data span is from the first quarter of 1970 through the fourth quarter of 1985 . The source of data is the Center for Economic Analysis, University of Colorado, Boulder, Colorado.

\section{Model Estimation}

The variables involved in the six-variable VAR model are the real oil price (ROILP), interest rate (FYGN3), real GNP (RGNP), total nonfarm employment (EECS), real personal income (RPYCS), and the Colorado consumer price index (CPIC). As explained in the procedural section, the FPE criterion is used to select the lag structure of the model. As a diagnostic check, the residual cross-correlation matrices also are calculated. The estimated model and the matrices are presented in Table 1.

The first equation of ROILP in Table 1 [ $\log$ and difference of ROILP henceforth denoted by ROILP] contains no other variables, indicating that this variable is purely exogenous to all other variables in the system. Similarly, the first three equations contain no local variables, a restriction indicating block exogeneity of the first three macro-variables (ROILP, FYGN3, and RGNP) to remaining local variables (EECS, RPYCS, and CPIC). These two propositions about exogeneity are tested by using the likelihood ratio tests presented in Table 2.

Exogeneity of the oil price and the block exogeneity of the three macrovariables were not rejected at the five percent level of significance. The proposition that the oil price is exogenous to all the variables in the system, including two national variables, FYGN3 and RGNP, indicates that the U.S. economy has no effect on the movements of the oil price. The second proposition that the Colorado economy is strongly endogenous to national economic activity is quite understandable. In other words, there is no feedback from Colorado variables to the national economy.

The residual cross-correlation matrices presented in Table 1 suggest that the residuals are white noise. Only four out of 108 elements (3.7 percent) are significantly different from zero. Thus, the dynamic structure indicated by the estimated VAR is considered to be compatible with 
Table 1

Estimated Vector Autoregression Model of the Colorado Economy, 1970 - 1985

$$
\begin{aligned}
& \text { ROILP }_{\mathrm{l}}=0.537 \text { ROILP }_{\mathrm{l}-1} \\
& \text { (0.110) } \\
& \text { FYGN3 }_{t}=0.311 \text { FYGN3 }_{t-1}-0.390 \text { FYGN3 }_{t-2}+0.281 \text { FYGN3 }_{t-3}+3.224 \text { RGNP }_{t-1} \\
& \begin{array}{llll}
(0.108) & (0.104) \quad(0.106)
\end{array} \\
& \text { RGNPt }=0.006-0.057 \text { ROILP }_{t-3}+0.181 \text { RGNP }_{t-1} \\
& (0.001)(0.017) \quad(0.100)
\end{aligned}
$$

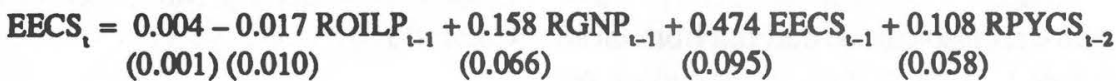

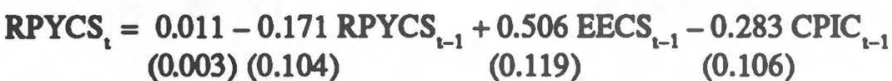

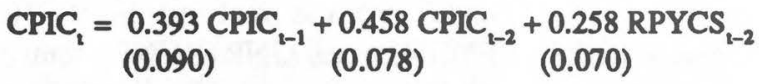

Note: Standard errors are in parentheses.

All variables are logged and differenced once.

Residual Cross-correlation Matrices

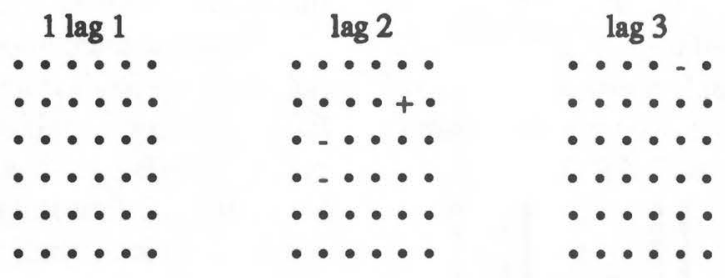

the data.

\section{Analysis of Innovations}

Following the innovation-accounting technique of Sims (1980), an attempt is made to measure the impact of oil price shocks on the Colorado economy. First, the final estimated VAR is converted to a moving average represen- tation, and the unique (uncorrelated) impulse responses are generated. These responses usually are useful in analyzing the direction of responses. The impulse response weights show the responses to shocks equal to positive residuals of one standard deviation. These results are sensitive to the ordering of the variables. The ordering used here is ROILP, FYGN3, RGNP, EECS, RPYCS, and CPIC. This ordering assumes, for example, that the ROILP innovation

Table 2

Results of Exogeneity Tests of Variables in the Estimated Vector Autoregression Model of the Colorado Economy, 1970-1985.

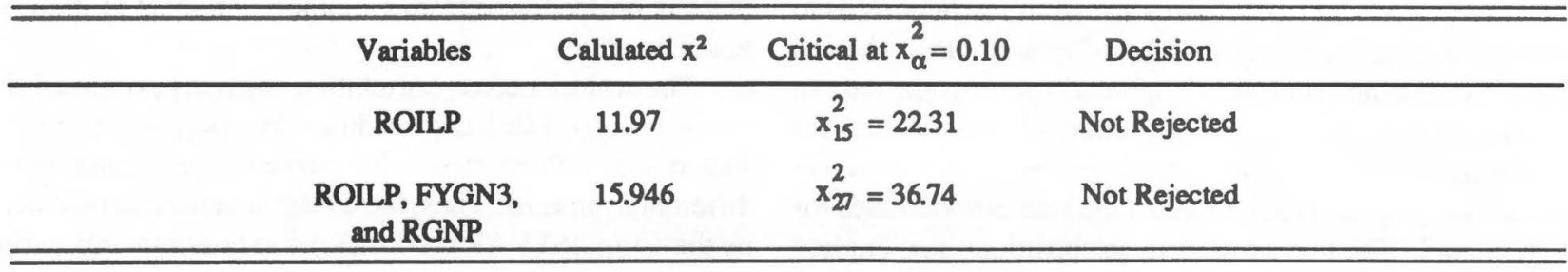


disturbs all other variables. In this case, since the first three variables were found to be exogenous to the last three, the ordering is theoretically plausible. In other words, the triangularization of the system usually required for such innovation analysis was not imposed in an ad hoc manner. The orthogonalization based on the Choleski transformation adopted here preserves this triangularization.

The unique response weights have been plotted and presented in Figure 1. The second graph in Figure 1 shows how RGNP responds to a unit shock in the real oil price. The responses of RGNP to oil price innovation are negative after the second quarter and remain negative until the multiplier effect dies out. The initial positive response in RGNP may have been caused by increased stimulation of economic activity in the oil-producing states. Initially, the interest rate also responds positively, primarily because of the inflationary effect of the rising oil price. In the later periods, responses of the interest rate are negative. Fear of recession might have caused the interest rate to decline.

The third, fourth, and fifth graphs in Figure 1 show the responses of the regional variables (employment, income and price) to oil price innovations. Both the employment and real income variables for the Colorado economy responded negatively. This is consistent with the situation in the 1970s in Colorado, which involved a rapid growth in the energy sectors, followed by dampening economic activity due to lower real personal income (Hunt and Oldham, 1986). In addition, a decline in the growth of real GNP contributed to the suffering of the Colorado economy. This analysis presented here shows that a positive shock in GNP innovations has a positive impact on regional variables (employment and income). Therefore, any negative impact on the national economy due to a rising oil price will affect the Colorado economy adversely. The fifth graph in Figure 1 shows that after a few quarters, the Colorado price index responds negatively to the real oil price shocks. This response is mainly due to falling demand caused by lower real income and lower employment. The values of the impulse responses plotted on the graphs converge toward zero after a few quarters, implying that the model is stable.

Table 3 displays the decomposition of the forecast error variances, which is useful in locating the channels of influence. A variable that is strictly exogenous will have entries of 100.0 in its diagonal cell, with zeros in all other cells in its column. An exogenous variable with entries 100.0 in its cell implies that the innovations of this variable account for all of its variance (Sims, 1980). Thus, reading across the rows shows how a unit shock in a particular variable influences all other variables. Or, reading down a column indicates the proportions of the forecast errors in the particular variable (shown on the top of the column) is explained by all other variables.

Reading down the column for variable RGNP indicates that even after 24 steps, oil price shocks (ROILP) explain about 17 percent of the variation in RGNP, leaving 83 percent explained by the innovations of RGNP. Notice that the value at the first step is 0.4 , implying that RGNP does not respond immediately to an oil price innovation. In fact, up to second quarter RGNP is quite unaffected by oil price shock. A similar delayed effect of oil price changes on RGNP was found by Hamilton (1983). About 91 percent of the variation in FYGN3 is explained by itself, with about 8 percent explained by RGNP. As far as the oil price is concerned, it has no sizable influence on FYGN3. Interest rate innovations seem unimportant in explaining RGNP, as is implied by the autoregression form of the model.

The important influences of oil price shock for GNP growth in the United States also have been found by Hamilton (1983). Burbidge and Harrison (1984) use of the VAR approach and reported a similar result for first oil price rises after September 1973. However, they indicated that the influence of the oil price was quite minimal for the second set of increases in April 1979. Hamilton and the author of this report use quarterly GNP data, whereas Burbidge and Harrison used monthly industrial production data.

Turning to regional variables, the main source of influence on the Colorado economy is the growth of RGNP. The RGNP explains about 26 percent of the variation in EECS and about 21 percent of that in RPYCS. It is interesting to note that oil price shocks have minimal effects on the regional economy. This can be seen by looking at the numbers in the EECS column in Table 3, where only 10 percent of the variation in EECS is explained by the oil price shock, and virtually none of that in RPYCS and CPIC. Recall also that the 10 percent effect on EECS is in the negative direction. This indicates that although an upward price shock may stimulate the regional economy via increased activities in energy-related sectors, a slack economy at the national level (caused by oil price shocks) influences the regional economy adversely, thereby offsetting the positive effects of a higher oil price.

The lack of a positive impact of oil price shock on the Colorado economy as indicated by this model is due to the local industry mix. As of 1985 , the oil and gas sector accounted for less than 2 percent of total non-agricultural employment. In fact, as far as the share of oil and gas employment is concerned, Colorado ranks lowest among the selected oil-producing states. According to 1984 figures, employment shares for the different states are Colorado (1.8 percent); Alaska (3.7 percent); Texas (four percent); Louisiana (4.9 percent); Oklahoma (6.1 percent); 
An Analysis of the Effect of Oil Price Shocks on the

Table 3

Decomposition of Forecast Error Variances: Variables in Estimated Vector Autoregression Model of the Colorado Economy, 1970-1985.

\begin{tabular}{|c|c|c|c|c|c|c|c|}
\hline \multirow{2}{*}{$\begin{array}{c}\text { Due to } \\
\text { Innovations in }\end{array}$} & \multirow{2}{*}{$\begin{array}{l}\text { Steps } \\
\text { Ahead }\end{array}$} & \multicolumn{6}{|c|}{ Percent Forecast Error of Variable } \\
\hline & & ROILP & FYGN3 & RGNP & EECS & RPYCS & $\overline{\mathrm{CPIC}}$ \\
\hline \multirow[t]{4}{*}{ ROILP } & 1 & 100.0 & 0.0 & 0.4 & 0.9 & 0.0 & 0.0 \\
\hline & 6 & 100.0 & 1.3 & 16.0 & 8.0 & 0.8 & 0.3 \\
\hline & 18 & 100.0 & 1.5 & 16.6 & 10.0 & 0.9 & 0.7 \\
\hline & 24 & 100.0 & 1.5 & 16.6 & 10.0 & 0.9 & 0.7 \\
\hline \multirow[t]{4}{*}{ FYGN3 } & 1 & 0.0 & 100.0 & 0.7 & 1.4 & 0.0 & 6.6 \\
\hline & 6 & 0.0 & 90.9 & 0.6 & 1.2 & 0.1 & 8.4 \\
\hline & 18 & 0.0 & 90.7 & 0.6 & 1.2 & 0.2 & 8.5 \\
\hline & 24 & 0.0 & 90.7 & 0.6 & 1.2 & 0.2 & 8.6 \\
\hline \multirow[t]{4}{*}{ RGNP } & 1 & 0.0 & 0.0 & 98.9 & 13.6 & 21.6 & 2.4 \\
\hline & 6 & 0.0 & 7.8 & 83.4 & 26.0 & 20.8 & 2.4 \\
\hline & 18 & 0.0 & 7.8 & 82.8 & 25.4 & 20.6 & 3.8 \\
\hline & 24 & 0.0 & 7.8 & 82.8 & 25.4 & 20.6 & 3.8 \\
\hline \multirow[t]{4}{*}{ EECS } & 1 & 0.0 & 0.0 & 0.0 & 84.0 & 9.0 & 0.1 \\
\hline & 6 & 0.0 & 0.0 & 0.0 & 62.2 & 12.8 & 3.7 \\
\hline & 18 & 0.0 & 0.0 & 0.0 & 60.6 & 12.8 & 6.7 \\
\hline & 24 & 0.0 & 0.0 & 0.0 & 60.6 & 12.8 & 6.7 \\
\hline \multirow[t]{4}{*}{ RPYCS } & 1 & 0.0 & 0.0 & 0.0 & 0.0 & 69.3 & 55.3 \\
\hline & 6 & 0.0 & 0.0 & 0.0 & 2.5 & 63.8 & 43.3 \\
\hline & 18 & 0.0 & 0.0 & 0.0 & 2.5 & 63.4 & 39.8 \\
\hline & 24 & 0.0 & 0.0 & 0.0 & 2.5 & 63.4 & 39.7 \\
\hline \multirow[t]{4}{*}{ CPIC } & 1 & 0.0 & 0.0 & 0.0 & 0.0 & 0.0 & 35.4 \\
\hline & 6 & 0.0 & 0.0 & 0.0 & 0.1 & 1.8 & 40.7 \\
\hline & 18 & 0.0 & 0.0 & 0.0 & 0.2 & 2.1 & 40.5 \\
\hline & 24 & 0.0 & 0.0 & 0.0 & 0.2 & 2.1 & 40.5 \\
\hline
\end{tabular}

and Wyoming (8.6 percent) (Hunt and Oldham, 1986). Since the employment share of the oil and gas sector in Colorado is so small, any positive impact of oil price shocks in the oil and gas sector is more than offset by slackness in other sectors. Slower economic growth at the national level also affects the overall regional economy.

Looking at the interaction among regional variables, employment is an important factor in explaining variations in income in Colorado. The employment variable, EECS, explains about 13 percent of the variation in RPYCS. Similarly, real income accounts for about 40 percent of the variation in CPIC.

\section{Conclusions}

It has been demonstrated that the time series model can be applied to regional modeling. A six-variable VAR with three macrovariables and three regional variables has been modeled as a system. Three macrovariables are found to be block exogenous to remaining state variables. The price of oil is found to be exogenous to all other variables in the system.

The channels of influence have been studied via impulse response weights and variance decompositions. Figure 1 presents plots of the impulse responses. Consistent with other works, the real oil price shocks are found to exert a strong negative effect on real GNP.

The variance decompositions are presented in Table 3. Macrovariable real GNP is the most important factor in explaining the variation in employment and income in Colorado. The effects of oil price shocks on the Colorado economy are found to be rather weak and negative. There 
are two main reasons for the negative impact. First, the oil and gas sector of the Colorado economy contributes relatively little to employment and wages and salaries. Compared to five other major oil-producing states - Alaska, Louisiana, Oklahoma, Texas and Wyoming - Colorado is least dependent on the oil and gas sector, with only 1.8 percent of its employment in that sector. Second, when the national economy suffers from an oil price shock, the impact is felt in the regional economy through various channels. This means that any positive effects of increased activities in energy-related sectors in Colorado are more than offset by slower growth in other sectors and in the real GNP. In a nutshell, the Coloradoeconomy does not benefit from oil price increases.

\section{References}

Bohara, A. K. "Multivariate Time Series Models and Structural Econometric Model Specification." Unpublished Ph.D. Dissertation. Boulder, Colo.: University of Colorado, 1986. Michael G. Bradley, and Robert F. McNown. "New Evidence on Targets for Monetary Policy." Southern Economic Journal. 53:3 (1987).

Bruno, M. "Adjustment and Structural Change Under Supply Shocks." Scandinavian Joumal of Economics. 84 (1982). 199-221.

Burbidge, J., and Alan Harrison. "Testing for the Effects of OilPrice Rises Using Vector Autoregressions." International Economic Review, 25:2 (1984). 459-484.

Caines, P. E., C. W. Keng, and S. P. Sethi. "Causality Analysis and Multivariate Autoregressive Modeling with an Applica- tion to Supermarket Sales Analysis." Journal of Economic Dynamics and Control. 3 (1981). 267-98.

Fackler, J. S. "An Empirical Analysis of the Markets of Goods, Money, and Credit." Journal of Money. Credit. and Banking. 17:1 (1985). 28-42.

Hamilton, J. D. "Oil and the Macroeconomy since World War II." Journal of Political Economy. 91:2 (1983). 228-248.

Harkness, J. "Intermediate Imports, Expectations, and Stochastic Equilibrium Under Flexible Exchange Rates." Canadian Journal of Economics. 15 (1982). 118-143.

Hunt, G. L., and J. Oldham. "The Oil and Gas Sector of the Colorado Economy." Economic Review. Center for Economic Analysis, University of Colorado, Boulder, Colo. (May 1986). 11-20.]

Sims, C. A. "Macroeconomics and Reality." Econometrica. 48 (1980). 1-48.

Tatom, J. A. "Energy Prices and Short-Run Economic Performance." Federal Reserve Bank of St. Louis Review. 63:1 (1981). 3-17.

Tiao, G. C., and G. E. P. Box. "Modeling Multiple Time Series with Applications." Joumal of the American Statistical Association. (1981). 802-16. , and R. S. Tsay. "Multiple Time Series Modeling and Extended Sample Cross Correlations." Joumal of Business and Economic Statistics. (1983). 43-56.

Trezy, G. I., and B. H. Stevens. "The TFS Regional Modeling Methodology." Regional Studies. (1986). 547-62.

Wold, H. A Study in the Analysis of Stationary Time Series. Stockholm, Sweden: Almquist and Wiksell, 1954.

Zellner, A., and F. Palm. "Time Series and Structural Analysis of Monetary Models of the U.S. Economy." Sankya. Series C. 37 (1975). 12-56. 